\title{
Sporothrix in Korea
}

Moon Hyung You, Joon Goon Kim, Yeon Woong Kim, Dong Hoon Shin, Jong Soo Choi, Jee Bum Lee* Department of Dermatology, Yeungnam University College of Medicine, Daegu, Korea Department of Dermatology, Chonnam National University College of Medicine, Gwangju, Korea*

\section{Background and Objectives:}

Sporotrichosis is a chronic cutaneous fungal infection caused by Sporothrix (S.) schenckii complex.

Sporotrichosis was common deep mycosis in Korea. All strains were reported as $S$. schenckii. There was no molecular studies until 2016. In northeast China and Japan, S. globosa was main species of Sporothrix, and $S$. schenckii sensu stricto was very rare.

We want to know accurate species of Korean strains reported as S. schenckii.

\section{Methods:}

We searched the Korean strains of Sporothrix spp. at fungus collection centers or private collections and reviewed literatures of molecular studies for Korean strains. We found 6 strains of $S$. schenckii and 3 strains of $S$. globosa. Ribosomal DNA ITS sequences were compared with those of the species of Sporothrix schenckii complex.

\section{Results:}

Ribosomal ITS sequences of 9 strains were $100 \%$ identical with S. globosa. There was no $S$.

schenckii sensu stricto.

We found one study about molecular analysis of

Korean S. schenckii (Ishizaki et al., 2004). All of 8 strains of Korean S. schenckii were mitochondrial type Group B, that was identical with S. globosa.

So all 17 strains of Korean S. schenckii complex were $S$ globosa.

\section{Conclusion:}

S. globosa is the causative species in tested Korean sporotrichosis.

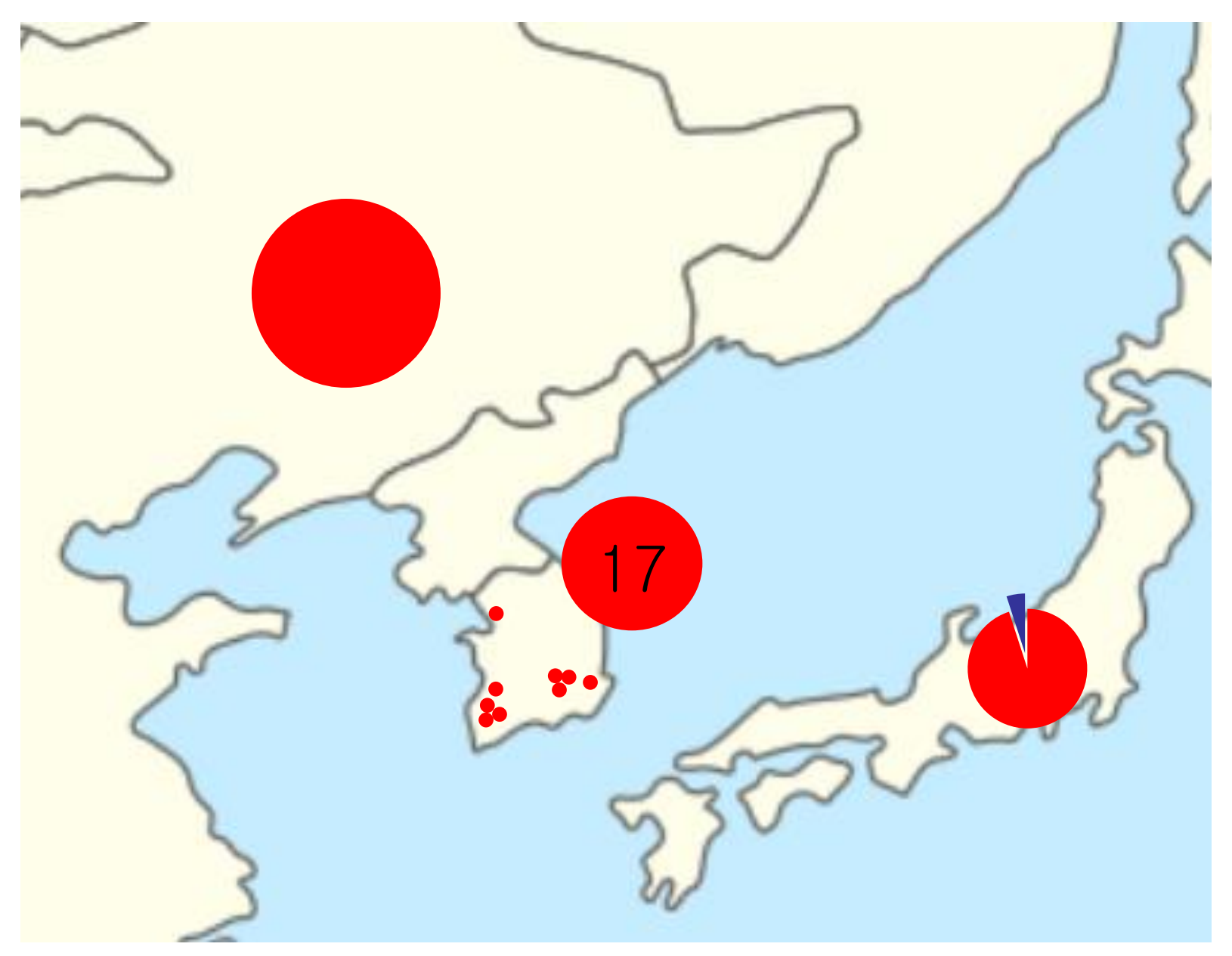

Fig. 1. Distribution of Sporothrix species in northeast China, Korea, and Japan. Blue, local populations of $S$. schenckii; red, local populations of $S$. globosa. Seventeen cases of sporotrichosis reported in Korea was found to be due to $S$. globosa.
Table 1. Strains Sporothrix found in South Korea

$\begin{array}{ccccccc}\text { No } & \text { Year } & \text { Area } & \text { Source } & \text { Reported as } & \text { rDNA ITS } \\ 1 & 1998 & \text { Gwangju } & \text { Human skin } & \text { S. schenckii } & \text { S. globosa } \\ 2 & 2009 & \text { Gwangju } & \text { Human skin } & \text { S. schenckii } & \text { S. globosa } \\ 3 & 2009 & \text { Gwangju } & \text { Human skin } & \text { S. schenckii } & \text { S. globosa } \\ 4 & 2014 & \text { Gyeungju } & \text { Human skin } & \text { S. schenckii } & \text { S. globosa } \\ 5 & 2015 & \text { Daegu } & \text { Human skin } & \text { S. globosa } & \text { S. globosa } \\ 6 & 2016 & \text { Daegu } & \text { Human skin } & \text { S. globosa } & \text { S. globosa } \\ 7 & 2017 & \text { Daegu } & \text { Human skin } & \text { S. globosa } & \text { S. globosa } \\ 8 & 2018 & \text { Seoul } & \text { Human skin } & \text { S. schenckii } & \text { S. globosa } \\ 9 & 2018 & \text { Jeonju } & \text { Human skin } & \text { S. schenckii } & \text { S.globosa }\end{array}$

Table 2. Mitochondrial DNA Analysis of Sporothrix schenckii from Korea by Ishizaki et al.

$\begin{array}{ccccc}\text { No } & \text { Year } & \text { Source Reported as } & \begin{array}{c}\text { mtDNA type } \\ \text { (Type/Group) }\end{array} & \text { rDNA ITS } \\ 1 & <2003 \text { Human skin S. schenckii } & 4 / B & \text { S. globosa } \\ 2 & <2003 \text { Human skin S. schenckii } & 4 / B & \text { S. globosa } \\ 3 & <2003 \text { Human skin S. schenckii } & 4 / B & \text { S. globosa } \\ 4 & <2003 \text { Human skin S. schenckii } & \text { 4/B } & \text { S. globosa } \\ 5 & <2003 \text { Human skin S. schenckii } & 4 / B & \text { S. globosa } \\ 6 & <2003 \text { Human skin S. schenckii } & 5 / B & \text { S. globosa } \\ 7 & <2003 \text { Human skin S. schenckii } & 5 / B & \text { S. globosa } \\ 8 & <2003 \text { Human skin S. schenckii } & 5 / B & \text { S. globosa }\end{array}$

Fig. 2. Phylogenetic tree of Korean strains of Sporothrix with rDNA ITS sequences (UPMA) 